\title{
Desempenho tecnológico dos serviços de abastecimento de água e esgotamento sanitário em quatro municípios de Minas Gerais: uma análise comparativa
}

\author{
Technological performance of water supply and sanitation services \\ in four municipalities in Minas Gerais, Brazil: a comparative analysis
}

\begin{abstract}
Pedro Gasparini Barbosa Heller
Engenheiro Civil pela Universidade Federal de Minas Gerais (UFMG). Doutorando em Saneamento, Meio Ambiente e Recursos Hídricos pela UFMG

Marcos Von Sperling

Engenheiro Civil e Sanitarista. Doutor em Engenharia Ambiental pelo Imperial College, Universidade de Londres. Pesquisador do Conselho Nacional de Desenvolvimento Científico e Tecnológico (CNPq). Professor Titular do Departamento de Engenharia Sanitária e Ambiental (Desa) da UFMG
\end{abstract}

\section{Léo Heller}

Engenheiro Civil e Sanitarista. Doutor em Epidemiologia pela UFMG. Pós-doutorado pela Universidade de Oxford, Inglaterra. Pesquisador do CNPq. Professor-associado do Desa da UFMG

\section{Resumo}

Indicadores tecnológicos representam uma importante forma de avaliar a quantidade e a qualidade dos serviços de saneamento prestados à população. Com essa perspectiva, o artigo apresenta metodologia quali-quantitativa, visando à comparação do desempenho tecnológico de serviços de água e esgotos. O modelo é constituído por indicadores de desempenho que, combinados por meio de análise multicritério (modelo TOPSIS), propiciam uma hierarquização da qualidade tecnológica dos serviços. Aplica-se a metodologia aos municípios de Itabirito, Ouro Preto, Nova Lima e Vespasiano (Minas Gerais). Buscando explorar as particularidades do desempenho de cada serviço, os resultados permitem identificar diferenças tecnológicas significativas entre eles, reveladas nos aspectos de cobertura por redes, controle de perdas, qualidade da água, estações de tratamento, tarifas, entre outros.

Palavras-chave: abastecimento de água; esgotamento sanitário; análise multicritério; desempenho tecnológico.

\section{Abstract}

Technological indicators are important tools for the assessment of quantity and quality of the environmental sanitation services provided for the population. From this perspective, this paper presents a quali-quantitative methodology intending to compare technological performance of water supply and sanitation services. The method consists of performance indicators that, combined trough a multicriterion model (TOPSIS), enable the hierarchization of the technological quality of services. The model is applied at the municipalities of Itabirito, Ouro Preto, Nova Lima and Vespasiano (Minas Gerais, Brazil). Exploring particularities of each service performance, the results suggest significant technological differences between the services, based on aspects of coverage, water loss control, water quality, treatment plants, tariffs, etc.

Keywords: water supply; sanitation; multicriterion analysis; technological performance.

\section{Introdução}

Apesar do consenso quanto à necessidade de se promoverem avaliações das políticas públicas, no Brasil, o arcabouço conceitual e metodológico que deve dar suporte a essa atividade ainda é muito incipiente (BELLONI; MAGALHÃES; SOUSA, 2003). Reconhecer o processo de formulação de uma determinada política setorial e avaliar o seu atual estágio é fundamental para repensá-la, em razão da 
busca de efetividade e do cumprimento dos requisitos de promoção da saúde, do ambiente e da qualidade de vida (COSTA, 2003).

No caso específico do saneamento, apesar de ainda embrionária, observa-se que a avaliação das políticas públicas é um campo que vem ganhando novos contornos, com o surgimento de importantes trabalhos, entre eles:

- Coutinho (2001), que comparou grupos de municípios do estado de Minas Gerais considerando as diferentes categorias de gestores de serviços de saneamento e adotando como referência os anos de 1989 e 1998. Os resultados indicam diferenças entre os gestores e que, além do bom desempenho da Companhia de Saneamento de Minas Gerais (Copasa) em alguns aspectos, as autarquias municipais destacaram-se positivamente;

- Costa (2003) que, ao avaliar a política nacional de saneamento implantada pelo Governo Federal entre 1996 e 2000, evidencia que, na medida em que os gestores da política não foram efetivos no aspecto central de sua agenda - a reorganização institucional privatizante - a efetividade alocativa foi reduzida e, em decorrência, a eficácia foi comprometida;

- Borja (2004) que, ao realizar avaliação da política de saneamento no estado da Bahia e do programa Bahia Azul, identificou a nãocapacidade do programa de promover um serviço justo do ponto de vista social e ambiental, apesar de sua grandeza financeira;

- Ogera e Phillippi (2005) ao analisarem a gestão dos serviços de água e esgotos em quatro municípios de São Paulo, sugeriram que as políticas públicas devem ser avaliadas num processo contínuo para aferir a eficácia dos serviços prestados, mediante confrontação com indicadores sociais;

- Rezende (2005) buscou avaliar os determinantes da presença de serviços públicos de abastecimento de água e esgotamento sanitário nos domicílios urbanos brasileiros. Evidenciou-se que, dentre os modelos de gestão, as maiores chances de presença de redes domiciliares pertencem aos municípios da Região Sudeste e com gestão do tipo autarquia.

Dentro da perspectiva das políticas públicas de saneamento, os aspectos tecnológicos apresentam um papel fundamental para a avaliação do desempenho dos serviços, o que os relaciona diretamente com a quantidade e a qualidade dos serviços prestados à população. A escolha de uma tecnologia adequada para uma região específica é fundamental para se atingirem níveis altos de cobertura com um serviço de boa qualidade.

Torregrosa et al (2004), ao avaliarem a dimensão tecnológica de sistemas de saneamento de diversos países, destacam que os prestadores de serviços, na maioria das vezes, se caracterizam por grandes 'consumidores' de água devido a elevadas perdas nas fases de produção e distribuição de seus sistemas.

Von Sperling (2004) alerta que a decisão para a escolha da tecnologia mais apropriada na implantação de infraestrutura sanitária deve ser tomada com independência de pressões externas, que poderiam estar direcionando a solução para uma alternativa menos adequada à realidade específica. $\mathrm{O}$ autor enfatiza que não existe uma solução global, ou seja, aplicável a todas as circunstâncias, e os decisores envolvidos devem estar abertos à escolha da melhor solução local.

O presente trabalho, a partir de metodologia construída, objetiva avaliar comparativamente o desempenho tecnológico dos serviços de abastecimento de água e esgotamento sanitário dos municípios de Itabirito, Nova Lima, Ouro Preto e Vespasiano, todos em Minas Gerais.

\section{Metodologia}

A avaliação comparativa entre os serviços de saneamento foi feita por meio de uma abordagem quali-quantitativa e foi desenvolvida no ano de 2007.

A avaliação quantitativa baseou-se em indicadores tecnológicos, construídos a partir de dados primários (questionário desenvolvido para a pesquisa) e complementados por dados secundários obtidos através das seguintes bases de dados: Instituto Brasileiro de Geografia e Estatística (IBGE), o Censo Demográfico de 2000, e Sistema Nacional de Informações sobre Saneamento (SNIS) de 2005. Já a avaliação qualitativa foi norteada pelas informações obtidas através de questionário e comentários expostos pelos dirigentes dos serviços de saneamento no momento de realização das visitas aos municípios, tendo dado suporte à discussão dos resultados. Os serviços selecionados, segundo população urbana e modelos de gestão, estão demonstrados na Tabela 1.

Como forma de substanciar a presente pesquisa, fez-se uso da análise multicritério, método TOPSIS (HWANG; YOON, 1981 apud POMEROL; BARBA-ROMERO, 2000; MOURA, 2004; CASTRO, 2007). O método busca avaliar a distância em relação a um ideal e a uma inversa, denominada de anti-ideal, por meio de uma 'taxa de similitude', sendo que:

- $\mathrm{d}^{\mathrm{M}}{ }_{1}\left(\mathrm{a}_{\mathrm{i}}\right)$ : distância entre os valores apresentados por cada município em relação ao valor ideal para cada critério utilizado na análise;

- $\quad \mathrm{d}_{1}^{\mathrm{m}}\left(\mathrm{a}_{\mathrm{i}}\right)$ : distância entre os valores apresentados por cada município em relação ao valor anti-ideal para cada critério utilizado na análise;

- $\mathrm{D}_{1}\left(\mathrm{a}_{\mathrm{i}}\right)$ t taxa de similitude: relação entre a distância referente ao valor anti-ideal e o somatório das distâncias referentes aos valores ideal e anti-ideal, ou seja, $\left\{\mathrm{d}^{\mathrm{m}}{ }_{1}\left(\mathrm{a}_{\mathrm{i}}\right)\right) /\left[\left(\mathrm{d}^{\mathrm{M}}{ }_{1}\left(\mathrm{a}_{\mathrm{i}}\right)+\mathrm{d}^{\mathrm{m}}{ }_{1}\left(\mathrm{a}_{\mathrm{i}}\right)\right]\right\}$.

A aplicação do método teve como finalidade a agregação dos indicadores construídos a partir dos estudos de caso e, consequentemente, a hierarquização da qualidade tecnológica ${ }^{1}$ dos serviços de saneamento, resultando em uma nota final para cada serviço avaliado. A articulação dos critérios (variáveis) selecionados 
Tabela 1 - Modelos de gestão dos serviços de saneamento estudados

\begin{tabular}{|c|c|c|c|}
\hline Distrito-sede (1) & Prestador do serviço & Descrição do gestor & Tarifação \\
\hline $\begin{array}{l}\text { Itabirito ( } 34.725 \text { hab.) Abastecimento de água e } \\
\text { esgotamento sanitário }\end{array}$ & Autarquia municipal & Saae Itabirito - Lei no 1016 em 11/07/1978 & Sistema com tarifação própria \\
\hline Nova Lima (63.035 hab.) Abastecimento de água & Companhia Estadual & $\begin{array}{l}\text { Copasa - concessão renovada em } 1998 \\
\text { com vigência de } 30 \text { anos }\end{array}$ & Tarifação única estadual \\
\hline Nova Lima (63.035 hab.) Esgotamento sanitário & Prefeitura Municipal & Prefeitura Municipal de Nova Lima & Sem tarifação \\
\hline $\begin{array}{l}\text { Ouro Preto (2) ( } 38.301 \text { hab.) Abastecimento de } \\
\text { água e esgotamento sanitário }\end{array}$ & $\begin{array}{l}\text { Prefeitura Municipal } \rightarrow \\
\quad \text { Autarquia Municipal }\end{array}$ & $\begin{array}{l}\text { Em processo de estruturação de uma } \\
\text { autarquia municipal }\end{array}$ & Sem tarifação \\
\hline $\begin{array}{l}\text { Vespasiano ( } 75.213 \text { hab.) Abastecimento de água } \\
\text { e esgotamento sanitário }\end{array}$ & Companhia Estadual & $\begin{array}{l}\text { Copasa - concessão renovada em } 2004 \\
\text { com vigência de } 30 \text { anos }\end{array}$ & Tarifação única estadual \\
\hline
\end{tabular}

Saae: Serviço Autônomo de Água e Esgoto.

Fonte da população dos distritos-sede: IBGE, Censo 2000; (2) a pesquisa considera Ouro Preto como sendo um serviço administrado diretamente pela própria Prefeitura Municipal.

para a alimentação do método TOPSIS deve ser feita a partir da ponderação de cada variável em relação à sua relevância para o desempenho tecnológico apresentado pelos serviços estudados. Como forma de garantir uma ponderação adequada desses critérios, foi realizada uma consulta a especialistas da área de saneamento, perfazendo um total de 31 pesquisados, com um total de respostas de 27.

Através de consulta a especialistas, cada variável foi ponderada em relação à sua relevância para o desempenho tecnológico apresentado pelos serviços estudados. Os valores adotados foram as medianas dos resultados obtidos pela consulta mediante quatro categorias possíveis: 1 - pouco importante, 2 - importante, 3 - muito importante e 4 - de fundamental importância.

Para a construção da planilha TOPSIS foram adotados os seguintes critérios:

- para os indicadores dicotômicos, foram atribuídos para sim e não respectivamente os valores de 1 e 0 ;

- para o indicador de amostras bacteriológicas (coliformes totais) fora do padrão na água de abastecimento, foram adotados os valores de um, caso não ultrapassasse a porcentagem de 5\% do total de amostras e zero caso esse valor fosse excedido. $\mathrm{O}$ valor de 5\% foi baseado na Portaria 518/2004, que estabelece esse limite para um período mensal de amostragem, apesar de os valores utilizados na análise terem sido anuais, para todo o ano de 2005;

- para o indicador de regularidade do abastecimento de água, atribuiu-se o seguinte critério: os valores possíveis foram 0,1 , 2 e 3, correspondentes ao número de problemas apresentados: descontinuidade de fornecimento de água, intermitências ou racionamentos, sendo que o valor zero indica uma ausência de problemas;

- para o indicador de proteção da captação atribuiu-se o seguinte critério: os valores possíveis foram 0, 1, 2 e 3, correspondentes ao número de condições apresentadas (vigilância, cercamento da área ou preservação da vegetação), sendo que o valor zero indica uma ausência de problemas;
- os indicadores que influenciam negativamente a qualidade dos serviços, no caso, perdas, amostras fora do padrão de qualidade da água e regularidade do abastecimento, tiveram seus valores expressos de forma inversa, ou seja, (1/ indicador).

A descrição dos indicadores construídos objetivando a caracterização do desempenho tecnológico dos serviços pode ser evidenciada no Quadro 1.

Quadro 1 - Indicadores tecnológicos utilizados para a caracterização dos sistemas estudados

\section{Abastecimento de água}

1 Existência de plano diretor de abastecimento de água

2 Proteção dos mananciais - sob as seguintes condições: vigilância, cercamento da área, preservação da vegetação, proibição de despejos e ausência de fontes poluidoras

3 Existência de outorga para captação

4 Cobertura por rede de água (\%) - (número de domicílios atendidos por rede de água) $\div$ (número de domicílios particulares permanentes)

5 Existência de cadastro de rede de distribuição

6 Índice de perdas na distribuição (\%) - [volume de água (produzido - de serviço) - volume de água consumido]/[volume de água (produzido - de serviço)]

7 Existência de programa de controle de perdas físicas

8 Regularidade do abastecimento - relativo à continuidade, à intermitência e ao racionamento na distribuição de água

9 Amostras de cloro residual fora do padrão (\%) - (média de amostras de cloro residual com resultados fora do padrão)/(quantidade de amostras analisadas para esses parâmetros)

10 Amostras de turbidez fora do padrão (\%) - (média de amostras de turbidez com resultados fora do padrão)/(quantidade de amostras analisadas para esses parâmetros)

11 Amostras bacteriológicas fora do padrão (\%) - (número de amostras de coliformes totais com resultado fora do padrão)/(quantidade de amostras analisadas para esses parâmetros)

12 Utilização de jar test no tratamento de água

13 Critério para lavagem de filtros da ETA - identificação do critério para lavagem de filtro adotado (perda de carga, turbidez da água filtrada, outro)

14 Controle automatizado de dosagem de produtos químicos na ETA

\section{Esgotamento sanitário}

15 Existência de plano diretor de esgotamento sanitário

16 Cobertura por rede de esgotos (\%) - (número de domicílios atendidos por rede de esgotos) $\div$ (número de domicílios particulares permanentes)

17 Existência de cadastro de rede coletora de esgotos

18 Adoção de sistema separador absoluto

19 Índice de esgoto tratado - (volume de esgoto coletado e tratado)/ (volume de esgoto coletado)

\footnotetext{
${ }^{1}$ A determinação da qualidade tecnológica dos serviços de água e esgotos dos municípios foi norteada pelo conceito de tecnologia apropriada (entendida como aquela que seja higienicamente segura, técnica e cientificamente satisfatória, social e culturalmente aceitável, não impactante ao ambiente e economicamente viável).
} 


\section{Resultados}

\section{Síntese das informações e dados relevantes levantados}

As Tabelas de 2 a 7 referem-se aos aspectos de abastecimento de água e esgotamento sanitário dos serviços de saneamento contemplados pela pesquisa.

\section{Análise multicritério}

A partir da definição pela consulta aos especialistas dos pesos (grau de importância correspondente aos números 1, 2, 3 e 4), de acordo com a classificação apresentada anteriormente e a partir dos valores obtidos para cada variável, desenvolveu-se a Tabela 8. Cabe destacar que se atribuíram os valores 1 e 0 para os indicadores dicotômicos (sim/não)

Tabela 2 - Aspectos dos mananciais da captação de água dos serviços estudados

\begin{tabular}{lcccc} 
Aspectos & Itabirito & Nova Lima & Ouro Preto & Vespasiano \\
\hline Tipo de manancial & Superficial & Superficial & Superficial/subterrânea & Superficial/subterrânea \\
Outorga & Sim & Sim & Sim & Não \\
Nível de proteção & $\begin{array}{c}\text { Área cercada, vegetação } \\
\text { preservada, vigilância }\end{array}$ & $\begin{array}{c}\text { Área cercada, vegetação } \\
\text { preservada, vigilância }\end{array}$ & $\begin{array}{c}\text { Área cercada, vegetação } \\
\text { preservada }{ }^{(2)}\end{array}$ & Área cercada, vigilância ${ }^{(3)}$ \\
Fontes de poluição & Atividade mineradora ${ }^{(1)}$ & Esgoto sanitário, assoreamento. & Não & Não \\
\hline
\end{tabular}

Fonte: Questionário aplicado aos serviços de saneamento estudados.

(1) a atividade mineradora refere-se a apenas uma das captações existentes; (2) o nível de proteção do sistema de Ouro Preto refere-se à captação superficial; (3) o nível de proteção de Vespasiano refere-se à captação subterrânea.

Tabela 3 - Sistemas de tratamento da água distribuída nos serviços estudados

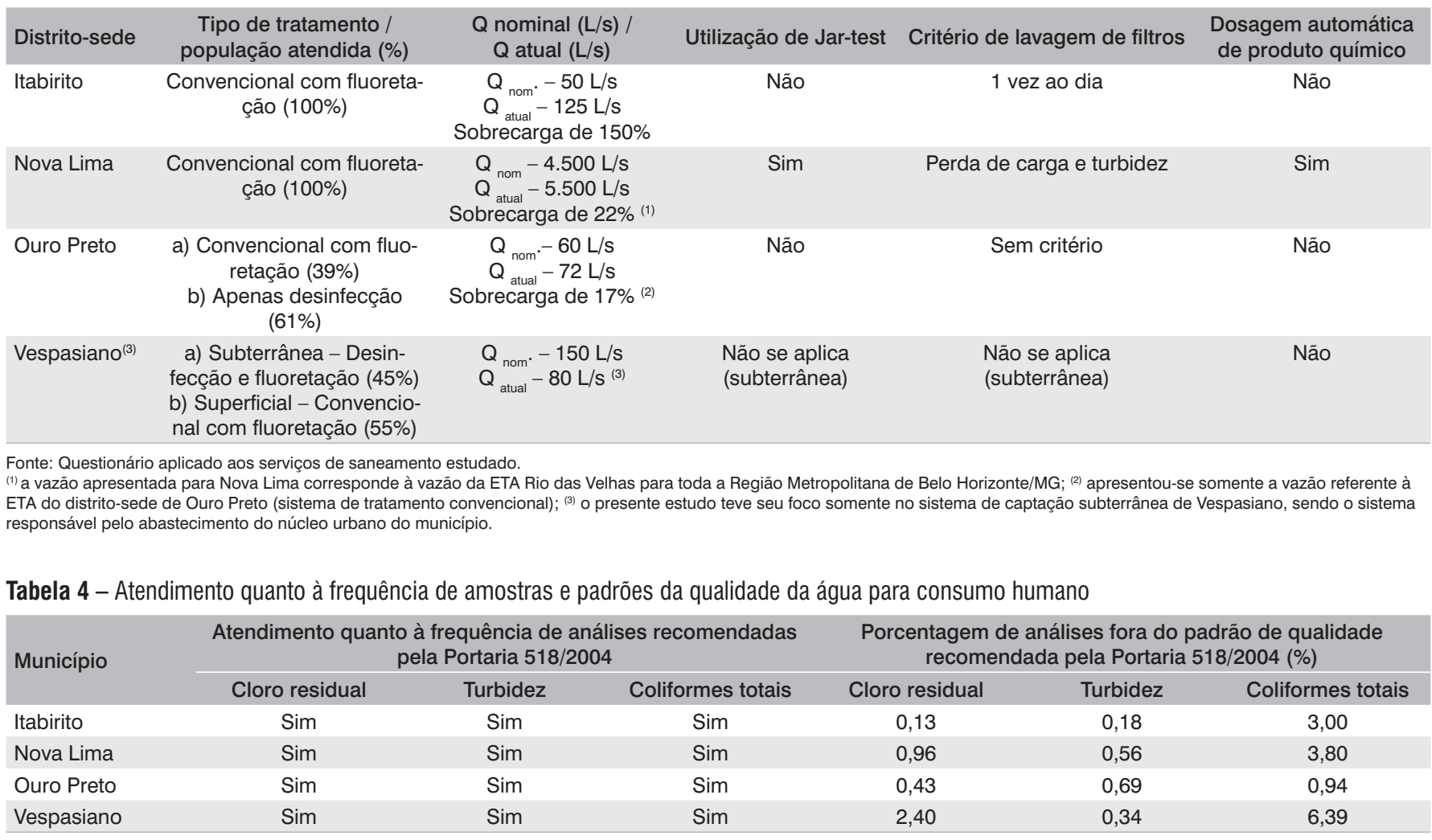

Fonte: SNIS, 2005

Tabela 5 - Aspectos dos sistemas de distribuição de água dos serviços estudados

\begin{tabular}{lcccc} 
Distrito-sede & $\begin{array}{c}\text { Cobertura por rede de } \\
\text { distribuição de água } \mathbf{( 1 )}^{(\%)}\end{array}$ & $\begin{array}{c}\text { Índice de perdas na } \\
\text { distribuição (\%) }\end{array}$ & $\begin{array}{c}\text { Controle de } \\
\text { perdas }\end{array}$ & Cadastro de redes/atualização \\
\hline Itabirito & 89,69 & 41,56 & Não & Não \\
Nova Lima & 91,96 & 45,09 & Sim & Sim (atualizado) \\
Ouro Preto & 94,61 & $50,00(2)$ & Não & Não \\
Vespasiano & 94,33 & 49,52 & Sim & Sim (atualizado) \\
\hline
\end{tabular}

Fonte: Questionário aplicado aos serviços de saneamento estudados e Censo 2000 do IBGE.

(1) os dados de cobertura são referentes ao Censo 2000 do IBGE; (2) o índice de perdas de Ouro Preto foi estimado em $50 \%$ a partir de informação do gestor local. 
Tabela 6 - Aspectos dos sistemas de coleta e interceptação de esgotos dos serviços estudados

\begin{tabular}{lccc}
\hline Distrito-sede & Cobertura por rede de esgotamento sanitário(1)(\%) & \multicolumn{1}{c}{ Tipo de sistema } & \multicolumn{2}{c}{ Cadastro de rede / atualização } \\
\hline Itabirito & 84,22 & separador absoluto & Não \\
\hline Nova Lima & 75,74 & $85 \%$ separador absoluto e 15\% unitário & Sim (em atualização) \\
\hline Ouro Preto & 86,53 & separador absoluto & Não \\
\hline Vespasiano(2) $^{(2)}$ & 46,73 & separador absoluto & Sim (atualizado) \\
\hline
\end{tabular}

Fonte: Questionário aplicado aos serviços de saneamento estudados e Censo 2000 do IBGE; Copasa (2006).

Os dados de cobertura por rede de esgotamento sanitário foram referentes ao Censo 2000 do IBGE; (2) Vespasiano foi o único serviço que apresentou ETE com um índice de esgoto coletado/tratado de $75 \%$.

Tabela 7 - Tarifas médias praticadas pelo Saae Itabirito e pela Copasa no ano de $2005\left(\mathrm{R} \$ / \mathrm{m}^{3}\right)$

\begin{tabular}{lcc} 
Serviço de saneamento & Abastecimento de água & Esgotamento sanitário \\
Saae Itabirito & 1,12 & 0,58 \\
Copasa Nova Lima & 1,88 & - \\
Copasa Vespasiano & 1,60 & 1,61 \\
\hline
\end{tabular}

Fonte: SAAE Itabirito e Copasa.

Tabela 8 - Identificação do ideal e do anti-ideal para os sistemas de abastecimento de água

\begin{tabular}{|c|c|c|c|c|c|c|}
\hline \multirow{2}{*}{ Critérios } & \multirow{2}{*}{ Unidade } & \multirow{2}{*}{ Peso } & \multicolumn{4}{|c|}{ Sistema } \\
\hline & & & ITA & NL & OP & VESP \\
\hline Plano diretor & - & 4 & 0,00 & 1,00 & 0,00 & 1,00 \\
\hline Proteção da captação & - & 4 & 3,00 & 3,00 & 2,00 & 3,00 \\
\hline Outorga & - & 3 & 1,00 & 1,00 & 1,00 & 0,00 \\
\hline Cobertura & $\%$ & 4 & 89,69 & 91,96 & 94,61 & 94,33 \\
\hline Cadastro de redes & - & 3 & 0,00 & 1,00 & 0,00 & 1,00 \\
\hline Perdas físicas & $\%$ & 3 & 41,56 & 45,09 & 50,00 & 49,52 \\
\hline Controle perdas físicas & - & 3 & 0,00 & 1,00 & 0,00 & 1,00 \\
\hline Regularidade no abastecimento & - & 4 & 2,00 & 2,00 & 3,00 & 2,00 \\
\hline Amostras de cloro residual fora do padrão & $\%$ & 4 & 0,13 & 0,96 & 0,43 & 2,40 \\
\hline Amostras de turbidez fora do padrão & $\%$ & 4 & 0,18 & 0,56 & 0,69 & 0,34 \\
\hline Amostras de coliformes totais fora do padrão & - & 4 & 1,00 & 1,00 & 1,00 & 0,00 \\
\hline Jar-test & - & 3 & 0,00 & 1,00 & 0,00 & 1,00 \\
\hline Critério lavagem filtros & - & 3 & 0,00 & 1,00 & 0,00 & 1,00 \\
\hline Controle automatizado ETA & - & 2 & 0,00 & 1,00 & 0,00 & 0,00 \\
\hline
\end{tabular}

ITA: distrito-sede de Itabirito; NL: distrito-sede de Nova Lima; OP: distrito-sede de Ouro Preto; VESP: distrito-sede de Vespasiano.

Tabela 9 - Ponderação e pontuação dos critérios para os sistemas de abastecimento de água

\begin{tabular}{|c|c|c|c|c|c|c|c|}
\hline \multirow{2}{*}{ Critérios } & \multirow{2}{*}{ Peso } & \multicolumn{4}{|c|}{ Sistema } & \multirow{2}{*}{ Ideal } & \multirow{2}{*}{ Anti-idea } \\
\hline & & ITA & NL & OP & VESP & & \\
\hline Plano diretor & 0,083 & 0,000 & 0,500 & 0,000 & 0,500 & 0,500 & 0,000 \\
\hline Proteção da captação & 0,083 & 0,273 & 0,273 & 0,182 & 0,273 & 0,273 & 0,182 \\
\hline Outorga & 0,063 & 0,333 & 0,333 & 0,333 & 0,000 & 0,333 & 0,000 \\
\hline Cobertura & 0,083 & 0,242 & 0,248 & 0,255 & 0,255 & 0,255 & 0,242 \\
\hline Cadastro de redes & 0,063 & 0,000 & 0,500 & 0,000 & 0,500 & 0,500 & 0,000 \\
\hline Perdas físicas & 0,063 & 0,278 & 0,257 & 0,231 & 0,234 & 0,278 & 0,231 \\
\hline Controle perdas físicas & 0,063 & 0,000 & 0,500 & 0,000 & 0,500 & 0,500 & 0,000 \\
\hline Regularidade no abastecimento & 0,083 & 0,273 & 0,273 & 0,182 & 0,273 & 0,273 & 0,182 \\
\hline Amostras de cloro residual fora do padrão & 0,083 & 0,670 & 0,091 & 0,203 & 0,036 & 0,670 & 0,036 \\
\hline Amostras de turbidez fora do padrão & 0,083 & 0,474 & 0,152 & 0,124 & 0,251 & 0,474 & 0,124 \\
\hline Amostras de coliformes totais fora do padrão & 0,083 & 0,333 & 0,333 & 0,333 & 0,000 & 0,333 & 0,000 \\
\hline Jar-test & 0,063 & 0,000 & 0,500 & 0,000 & 0,500 & 0,500 & 0,000 \\
\hline Critério lavagem filtros & 0,063 & 0,000 & 0,500 & 0,000 & 0,500 & 0,500 & 0,000 \\
\hline Controle automatizado ETA & 0,042 & 0,000 & 1,000 & 0,000 & 0,000 & 1,000 & 0,000 \\
\hline
\end{tabular}

ITA: distrito-sede de Itabirito; NL: distrito-sede de Nova Lima; OP: distrito-sede de Ouro Preto; VESP: distrito-sede de Vespasiano. 
Tabela 10 - Hierarquização dos sistemas de abastecimento de água pelo TOPSIS

\begin{tabular}{|c|c|c|c|c|}
\hline Sistema & $\mathrm{d}^{\mathrm{m}}{ }_{1}\left(\mathrm{a}_{\mathrm{i}}\right)$ & $\mathrm{d}^{\mathrm{m}}{ }_{1}\left(\mathrm{a}_{\mathrm{i}}\right)$ & $D_{1}\left(a_{i}\right)$ & Hierarquização \\
\hline Itabirito & $8590,52 \times 10^{-4}$ & $7050,50 \times 10^{-4}$ & $0,451 \times 10^{-4}$ & 3 \\
\hline Nova Lima & $5524,03 \times 10^{-4}$ & $9342,34 \times 10^{-4}$ & $0,628 \times 10^{-4}$ & 1 \\
\hline Ouro Preto & $9935,44 \times 10^{-4}$ & $3740,31 \times 10^{-4}$ & $0,273 \times 10^{-4}$ & 4 \\
\hline Vespasiano & $7801,01 \times 10^{-4}$ & $7661,96 \times 10^{-4}$ & $0,496 \times 10^{-4}$ & 2 \\
\hline
\end{tabular}

Tabela 11 - Ponderação e pontuação dos critérios para os sistemas de esgotamento sanitário

\begin{tabular}{|c|c|c|c|c|c|c|}
\hline \multirow{2}{*}{ Critérios } & \multirow{2}{*}{ Unidade } & \multirow{2}{*}{ Peso } & \multicolumn{4}{|c|}{ Sistema } \\
\hline & & & ITA & NL & OP & VESP \\
\hline Plano diretor & - & 4 & 1,00 & 0,00 & 0,00 & 0,00 \\
\hline Cadastro da rede coletora & - & 3 & 0,00 & 1,00 & 0,00 & 1,00 \\
\hline Cobertura & $\%$ & 3 & 84,22 & 75,74 & 86,53 & 46,73 \\
\hline Quantidade de rede do tipo separador absoluto & $\%$ & 2 & 100,00 & 85,00 & 100,00 & 100,00 \\
\hline Índice de esgoto tratado & $\%$ & 3 & 0,00 & 0,00 & 0,00 & 74,94 \\
\hline
\end{tabular}

ITA: distrito-sede de Itabirito; NL: distrito-sede de Nova Lima; OP: distrito-sede de Ouro Preto; VESP: distrito-sede de Vespasiano.

Tabela 12 - Identificação do Ideal e do Anti-ideal para os sistemas de esgotamento sanitário

\begin{tabular}{|c|c|c|c|c|c|c|c|}
\hline \multirow{2}{*}{ Critérios } & \multirow{2}{*}{ Peso } & \multicolumn{4}{|c|}{ Sistema } & \multirow{2}{*}{ Ideal } & \multirow{2}{*}{ Anti-idea } \\
\hline & & ITA & NL & OP & VESP & & \\
\hline Plano diretor & 0,267 & 1,000 & 0,000 & 0,000 & 0,000 & 1,000 & 0,000 \\
\hline Cadastro da rede coletora & 0,200 & 0,000 & 0,500 & 0,000 & 0,500 & 0,500 & 0,000 \\
\hline Cobertura por rede coletora & 0,200 & 0,287 & 0,258 & 0,295 & 0,159 & 0,295 & 0,159 \\
\hline Sistema separador absoluto & 0,133 & 0,260 & 0,221 & 0,260 & 0,260 & 0,260 & 0,221 \\
\hline Índice de esgoto tratado & 0,200 & 0,000 & 0,000 & 0,000 & 1,000 & 1,000 & 0,000 \\
\hline
\end{tabular}

ITA: distrito-sede de Itabirito; NL: distrito-sede de Nova Lima; OP: distrito-sede de Ouro Preto; VESP: distrito-sede de Vespasiano.

Tabela 13 - Hierarquização dos sistemas de esgotamento sanitário pelo TOPSIS

\begin{tabular}{|c|c|c|c|c|}
\hline Sistema & $d^{M}{ }_{1}\left(a_{i}\right)$ & $d^{m}{ }_{1}\left(a_{i}\right)$ & $D_{1}\left(a_{i}\right)$ & Hierarquização \\
\hline Itabirito & $22361,23 \times 10^{-4}$ & $26.794 \times 10^{-4}$ & $0,545 \times 10^{-4}$ & $1^{\circ}$ \\
\hline Nova Lima & $33346,50 \times 10^{-4}$ & $10.194 \times 10^{-4}$ & $0,234 \times 10^{-4}$ & $3^{\circ}$ \\
\hline Ouro Preto & $34801,02 \times 10^{-4}$ & $2.764 \times 10^{-4}$ & $0,074 \times 10^{-4}$ & $4^{\circ}$ \\
\hline Vespasiano & $26804,49 \times 10^{-4}$ & $22.367 \times 10^{-4}$ & $0,455 \times 10^{-4}$ & $2^{\circ}$ \\
\hline
\end{tabular}

A partir dos resultados obtidos, realizou-se uma parametrização dos pesos e dos critérios para cada serviço de saneamento, que consistiu em dividir o valor de cada critério apresentado pela soma de todos os valores, inclusive o apresentado pelo sistema em questão (Tabela 9).

Como exemplo, pode-se citar a parametrização do critério de cobertura de Ouro Preto, apresentado pela expressão a seguir.

Cob. OP parametrizada $(0,255)=($ cob. O.P: $94,61 \%) /(c o b$.

ITA: $89,61 \%+\operatorname{cob}$ N.L: $91,96 \%+$ cob. OP: $94,61 \%+$ cob. VESP

$94,33 \%)$.

Cabe destacar que os valores ideal e anti-ideal apresentados na Tabela 09 referem-se aos limites superior e inferior das pontuações obtidas, portanto, não refletem o que poderia ser o idealmente desejado (como uma cobertura por rede de 100\%) ou o não desejado para a caracterização tecnológica de um serviço, são apenas referentes aos valores dos serviços analisados.

Determinados os valores ideal e anti-ideal para os critérios selecionados, realizou-se a análise multicritério por meio do cálculo das distâncias em relação ao valor ideal e ao anti-ideal e consequentemente da taxa de similitude. O valor obtido de taxa de similitude para cada serviço analisado refere-se ao valor utilizado para a hierarquização dos serviços, de maneira que o serviço que apresentou a maior taxa foi classificado como primeiro do ranking, correspondendo ao melhor desempenho tecnológico na avaliação comparativa (Tabela 10).

A análise multicritério foi também aplicada aos serviços de esgotamento sanitário dos municípios estudados. A Tabela 11 apresenta os pesos e os valores atribuídos aos critérios que constituíram a análise. Seguiu-se o mesmo procedimento adotado para o campo de abastecimento de água.

Realizou-se, também, uma parametrização dos pesos e critérios para cada serviço de esgotamento sanitário visando à determinação dos valores ideal e anti-ideal, conforme se evidencia na Tabela 12

A Tabela 13 apresenta a hierarquização da qualidade tecnológica dos serviços estudados e também as variáveis de distância ao anti-ideal, distância ao ideal e taxa de similitude, conforme explicitadas anteriormente.

\section{Discussão}

Em relação ao abastecimento de água, o serviço de Nova Lima, operado pela Copasa, destaca-se como o serviço que apresentou o 
melhor desempenho tecnológico, seguido pelo serviço de água de Vespasiano, também operado pela Copasa, de acordo com a hierarquização obtida pelo método TOPSIS. Nova Lima destaca-se por apresentar uma ETA com unidades físicas em bom estado e operada de forma automatizada através de uma mesa de comando central. A ETA é responsável pelo abastecimento de água de grande parte da Região Metropolitana de Belo Horizonte, sendo o melhor sistema de operação observado entre as estações de tratamento. Pode também ser evidenciada a existência de plano diretor de abastecimento de água para Nova Lima e Vespasiano. O bom desempenho tecnológico desses municípios pode indicar o ganho que um serviço pode obter quando integrado a um sistema de maior abrangência, no caso o da região metropolitana de Belo Horizonte. Esse ponto sugere a potencialidade do emprego de consórcios intermunicipais e o consequente ganho de escala, conforme disciplinado na lei $n^{\circ} 11.107$, de 6 de abril de 2005, que dispõe sobre normas gerais para a União, os Estados, o Distrito Federal e os Municípios contratarem consórcios públicos para a realização de objetivos de interesse comum (BRASIL, 2005).

Como aspectos desfavoráveis na avaliação daqueles serviços, destacam-se os valores de tarifas médias praticadas, mais altas que as do Serviço Autônomo de Itabirito e, apesar da importância da ETA Rio das Velhas em Nova Lima, responsável pelo abastecimento da Região Metropolitana de Belo Horizonte, a presença de urbanização a montante da captação causa poluição por meio de despejos de esgotamento sanitário. Já em Vespasiano, foi registrada, além de tarifas médias altas, a presença de coliformes totais nas amostras de água analisadas. O modelo tarifário aplicado pela Copasa insere-se no princípio de subsídio cruzado adotado pelas CESB, no qual são cobradas tarifas únicas para todo o estado com a finalidade de que serviços superavitários cubram os déficits daqueles cujos custos sejam superiores às tarifas médias (BETTINE, 2003; REZENDE; HELLER, 2008).

O Serviço Autônomo de Itabirito foi classificado em terceiro lugar para o serviço de abastecimento de água, conforme resultado obtido por meio do método TOPSIS. O serviço se destaca por apresentar tarifa média por $\mathrm{m}^{3}$ de água de $\mathrm{R} \$ 1,12$, valor substancialmente menor do que os apresentados pelos serviços operados pela Copasa, de R\$1,60 para Vespasiano e R\$ 1,88 para Nova Lima. Destaca-se, também, pela boa qualidade da água distribuída à população, sendo, entre os serviços estudados, o que apresentou a menor proporção de amostras de parâmetros físico-químicos fora do padrão estabelecido pela Portaria do Ministério da Saúde 518/2004. Como aspecto negativo, identifica-se a presença de fontes poluidoras na bacia do manancial, tipo de problema apresentado também por Nova Lima. Percebe-se uma necessidade maior de planejamento de ações, já que o Saae Itabirito não possui um plano diretor de abastecimento de água, apesar de estarem previstas as ampliações da ETA e do sistema de distribuição.

Ouro Preto destaca-se com a classificação mais baixa entre os quatro municípios na hierarquização obtida através do método TOPSIS para o serviço de abastecimento de água, apresentando a menor taxa de similitude. O pequeno índice de tratamento de água fornecida à população destaca-se como uma significativa limitação tecnológica. Outro aspecto negativo apresentado pelo serviço é a problemática de racionamentos na distribuição de água, que atinge as populações mais carentes. Deve-se enfatizar o fato de que, no momento do estudo, Ouro Preto não cobrava tarifas pela distribuição de água e pela coleta de esgotos, o que pode ser considerado um impedimento para que o Serviço Municipal de Água e Esgoto de Ouro Preto (SEMAE$\mathrm{OP})$, ainda em estruturação, garanta sua sustentabilidade como uma autarquia municipal.

Avaliando comparativamente o limitado desempenho apresentado por Ouro Preto em relação ao apresentado pelo modelo autárquico de Itabirito, observa-se como uma autarquia, partindo-se do princípio fundamental da descentralização, pode mudar substancialmente o quadro tecnológico de um serviço de saneamento. Já os resultados apresentados pelos serviços operados pela Copasa, quando comparados aos resultados apresentados pelo modelo autárquico de Itabirito, não se demonstraram tão díspares, apesar de apresentarem particularidades. A Copasa se destaca pela tecnologia mais avançada empregada em seu sistema e por seus instrumentos de planejamento. Já Itabirito destaca-se por uma tarifa média significativamente menor e uma boa qualidade da água distribuída à população.

Quanto à cobertura por rede de água, todos os serviços estudados apresentaram valores elevados, em torno de 90\%. Apesar dos altos valores, deve-se considerar que a parcela da população não atendida por rede de água é a mais carente, desprovida de infraestrutura e frequentemente excluída das políticas públicas.

Apesar de Ouro Preto apresentar a maior proporção de domicílios ligados à rede de água, percebe-se uma menor equidade, definida em Brasil (2004A) como equivalência na qualidade sanitária dos serviços prestados à população. Isso por dois motivos principais: as diferenças na qualidade da água distribuída aos cidadãos, sendo apenas uma parcela tratada, e os racionamentos que atingem as populações mais carentes, habitantes das partes altas da cidade. Já Itabirito apresentou valor de cobertura bem próximo ao dos municípios operados pela Copasa, apesar de ser administrado por um modelo de gestão que não foi contemplado nos financiamentos disponibilizados pelo Plano Nacional de Saneamento (Planasa) (SEPURB, 1995 apud SOARES; NETO; BERNARDES, 2004)

Em relação ao índice de perdas, observa-se que todos os valores estão inseridos em uma faixa considerada alta e, apesar dos altos valores, apenas os municípios de Vespasiano e Nova Lima possuíam plano específico para o controle de perdas através de fiscalização de redes clandestinas, manutenção de hidrômetros e substituição de redes antigas. A elaboração desse plano de controle de perdas pode ser considerada uma ação eficaz - entendida como a extensão em que uma intervenção, procedimento ou serviço em condições ideais, produz um resultado benéfico do dispositivo ou do processo (HELLER; 
NASCIMENTO, 2005), porém não necessariamente efetiva - entendida como os resultados que um programa pode atingir, já que ainda não foram demonstrados.

Referente aos sistemas de esgotamento sanitário, o Saae de Itabirito foi o que apresentou o serviço com melhor qualidade tecnológica, de acordo com o método TOPSIS. Como aspectos positivos evidenciam-se a maior cobertura por rede coletora e a menor tarifa média. Também foi o único município que apresentou plano diretor de esgotos, em que foi prevista a implantação de interceptores e de uma ETE. A elaboração do Plano pode ser considerada uma ação eficaz, em que se percebe a importância dada pelo Serviço Autônomo a um instrumento de planejamento de ações, mas uma ação não efetiva, pois os sistemas previstos não foram implantados como o planejado.

Vespasiano aparece em segundo lugar em termos de desempenho tecnológico para o serviço de esgotamento sanitário, de acordo com a classificação obtida pelo método TOPSIS. O maior destaque apresentado pelo serviço é a existência de duas ETE do tipo lodo ativado, sendo o único serviço que apresentou tratamento para os esgotos. Apesar da existência de duas ETEs, o distrito-sede foi o que apresentou o valor de cobertura de coleta de esgotos mais baixo dentre os serviços avaliados, de apenas $46,73 \%$, que pode estar relacionado às altas tarifas praticadas.

Nova Lima, por sua vez, administrado por um modelo centralizado municipal, apresenta deficiências no serviço de esgotamento sanitário, e não foi encontrado nenhum aspecto positivo que se destacasse em relação aos outros serviços estudados. De acordo com o método TOPSIS, ocupa a penúltima posição em termos de desempenho tecnológico. Em relação aos outros serviços estudados, apresenta grandes problemas de obstrução nas redes devido ao lançamento de resíduos. Deve-se salientar que a avaliação desse serviço pode ter sido prejudicada devido à falta de informações disponíveis e à pequena atenção dada pelos gestores municipais à pesquisa. Nova Lima apresentou significativas diferenças entre o desempenho tecnológico para os serviços de água e esgotos. Percebe-se que o serviço, vinculado à administração municipal, não é adequadamente valorizado pela prefeitura, não sendo contemplado com a devida importância.

Como último classificado, na hierarquização feita pelo TOPSIS, encontra-se Ouro Preto, serviço também administrado pela própria prefeitura municipal. Foi evidenciada uma importância menor dada ao serviço de esgotamento sanitário pelos gestores do município, quando comparado com o serviço de abastecimento de água. Em relação à cobertura da coleta de esgotos, o valor apresentado pode ser considerado alto entre os serviços avaliados, bem próximo do valor de cobertura por rede de água, o que talvez possa ser justificado por ser um serviço em que não são cobradas tarifas.

\section{CONCLUSÕES}

Os resultados sugerem diferenças entre os serviços avaliados. Destacaram-se positivamente os serviços administrados por Companhia Estadual (serviço de água e esgotos de Vespasiano e serviço de água de Nova Lima) em termos de cadastro de redes, controle de perdas e alta tecnologia utilizada na operação dos sistemas e pelo Serviço Autárquico de Itabirito pelos baixos valores de tarifas praticados e pela alta cobertura por rede de esgotos. Por outro lado, os serviços diretamente administrados pelas Prefeituras Municipais de Nova Lima e Ouro Preto apresentaram mais baixo desempenho, apesar da alta cobertura por rede de água e de esgotos

A opção de pesquisa por um campo de análise constituído por apenas quatro municípios beneficiou-se do aprofundamento de análise do desempenho tecnológico dos serviços estudados. Com uma menor abrangência da amostra estudada, foi possível o desenvolvimento do trabalho com dados primários, obtidos em visitas aos municípios, o que possibilitou desvendar dimensões importantes desses serviços. Entretanto, deve-se atentar para o fato de que o estudo não aponta melhores ou piores serviços, mas particularidades que caracterizam o desempenho de cada serviço, que eventualmente são associadas aos seus respectivos modelos de gestão. Os comentários efetuados para cada município não devem ser avaliados em termos absolutos e isolados do contexto metodológico da presente pesquisa, mas em termos comparativos e de acordo com os critérios definidos no trabalho. Tais critérios foram os mais abrangentes possíveis, mas, naturalmente, não têm a pretensão de ser exaustivos.

O presente trabalho, ao desenvolver e aplicar uma metodologia para a avaliação e comparação de diferentes serviços de saneamento, procura contribuir metodologicamente com esse campo. Como foi visto, foram combinadas diferentes análises: análise quantitativa e qualitativa, com a utilização de dados primários e secundários; análise multicritério, além da construção e aplicação de questionário junto a especialistas. Acredita-se que tal sequência metodológica possa ser empregada em diversas situações e contribuir para revelar semelhanças e diferenças entre serviços de saneamento e, para amostras de maiores dimensões, inclusive para comparar diferentes modelos institucionais.

O país vive um período de mudanças institucionais para o setor de saneamento, com a aprovação da lei $n^{\circ} 11.445$ de 5 de janeiro de 2007, que estabelece diretrizes para o saneamento básico e a política federal de saneamento básico do país. Para que se cumpram os termos prescritos na lei, como os de regulação dos serviços de saneamento, de mecanismos de controle social e do planejamento de ações, o desenvolvimento de pesquisas acadêmicas que contemplem esse tipo de avaliação será de suma importância. 


\section{Agradecimentos}

Os autores agradecem aos funcionários e dirigentes dos serviços de saneamento estudados, aos integrantes da comissão examinadora da defesa de mestrado do primeiro autor, Professor Doutor Nilo de Oliveira Nascimento, Professor Doutor Rafael Kopschitz Xavier Bastos e Professora Doutora Sonaly Cristina Resende Borges de Lima. Por fim, agradecemos à Coordenação de Aperfeiçoamento de Pessoal de Nível Superior (Capes) pela concessão de bolsa de mestrado ao primeiro autor.

\section{Referências}

BELLONI, I.; MAGALHÃES, H.; SOUSA L.C. Metodologia de avaliação em políticas públicas. São Paulo: Cortez, 2003.

BETTINE, S.C. Instrumentos de regulação dos serviços de saneamento básico: um enfoque multiobjetivo. Tese (Doutorado) - Faculdade de Engenharia Civil da Unicamp, Campinas, São Paulo, 2003.

BORJA, P.C. Política de saneamento, instituições financeiras internacionais e mega-programas: um olhar através do Programa Bahia Azul. 400 f. Tese (Doutorado em Arquitetura e Urbanismo) - Faculdade de Arquitetura da UFBA, Salvador, Bahia, 2004.

BRASIL. Lei $n^{\circ} 11.445$, de 05/01/2007, que estabelece diretrizes nacionais para o saneamento básico e para a política federal de saneamento básico. Brasil, 2007.

Lei $n^{\circ} 11.107$, de 06/04/2005, que dispõe sobre normas gerais para a União, os Estados, o Distrito Federal e os Municípios contratarem consórcios públicos para a realização de objetivos de interesse comum. Brasil, 2005.

Ministério da Saúde. Organização Pan-Americana da Saúde. Avaliação do impacto na saúde das ações de saneamento: marco conceitual e estratégia metodológica. Brasília, DF: Ministério da Saúde, 2004A.

Ministério da Saúde. Portaria MS n 518, de 25 de março de 2004. Estabelece os procedimentos e responsabilidades relativos ao controle e vigilância da qualidade da água para consumo humano e seu padrão de potabilidade, e dá outras providências. Diário Oficial da União, Brasília, DF: Ministério da Saúde, 2004B.

CASTRO, L.M.A. Proposição de metodologia para avaliação da sustentabilidade da implantação de empreendimentos de desenvolvimento urbano. Tese (Doutorado em Saneamento, Meio Ambiente e Recursos Hídricos) - Escola de Engenharia, UFMG, Belo Horizonte, 2007

COPASA. Informações sobre a qualidade da água para consumo humano fornecida por sistema de abastecimento público - Relatório anual de controle da qualidade de Nova Lima e Vespasiano, 2004 a 2005. 2006. (Mimeo).

COSTA, A.M. Avaliação da política nacional de saneamento, Brasil - 1996/2000. 248 f. Tese (Doutorado em Saúde Pública) - Centro de Pesquisas Aggeu Magalhães, ENSP, Fundação Oswaldo Cruz, Recife, 2003.
COUTINHO, M.L. Comparação entre modelos de gestão dos serviços de abastecimento de água e de esgotamento sanitário, segundo indicadores de saúde pública, operacionais e sociais, nos municípios de Minas Gerais (1989 e 1998). 181 f. Dissertação (Mestrado em Saneamento, Meio Ambiente e Recursos Hídricos) - Escola de Engenharia, UFMG, Belo Horizonte, Minas Gerais, 2001.

HELLER, L.; NASCIMENTO, N.O. Pesquisa e desenvolvimento na área de saneamento no Brasil: necessidades e tendências. Revista Engenharia Sanitária e Ambiental, v. 10, n. 1, p. 24-35, 2005.

INSTITUTO BRASILEIRO DE GEOGRAFIA E ESTATÍSTICA. Censo demográfico, 2000. Disponível em http://www.ibge.gov.br/censo/ Acesso em: 15 nov. 2006.

MOURA, P.M. Contribuição para a avaliação global de sistemas de drenagem urbana. 164 f. Dissertação (Mestrado em Saneamento, Meio Ambiente e Recursos Hídricos) - Escola de Engenharia, UFMG, Belo Horizonte, Minas Gerais, 2004.

OGERA, R.C.; PHILIPPI, A. Gestão dos serviços de água e esgoto nos municípios de Campinas, Santo André, São José dos Campos e Santos, no período de 1996 a 2000. Revista Engenharia Sanitária e Ambiental, v. 10, n. 1, p. 72-81, 2005.

POMEROL, J.C.; BARBA-ROMERO, S. Multicriterion decision in management: principles and practice. Boston: Kluwer Academic Publishers, 2000.

PROGRAMA DE MODERNIZAÇÃO DO SETOR SANEAMENTO (PMSS). Sistema Nacional de Informações sobre Saneamento (SNIS) Diagnóstico dos serviços de água e esgotos, 2005. Secretaria Especial de Desenvolvimento Urbano da Presidência da República, Instituto de Pesquisa Econômica Aplicada, Programa de Modernização do Setor Saneamento, Brasília, DF, 2005.

REZENDE, S. Aspectos demográficos da cobertura de serviços de saneamento no Brasil urbano contemporâneo. 153 f. Tese (Doutorado em Demografia) - Faculdade de Ciências Econômicas da UFMG, Belo Horizonte, Minas Gerais, 2005.

REZENDE, S.C.; HELLER, L. O saneamento no Brasil: políticas e interfaces. 2. ed. Belo Horizonte: UFMG, 2008.

SOARES, S.R.A.; NETTO, O.M.C.; BERNARDES, R.S. Avaliação de aspectos político-institucionais e econômico-financeiros do setor de saneamento no Brasil com vistas à definição de elementos para um 
modelo conceitual. Revista Engenharia Sanitária e Ambiental, v. 8, n. 1, p. $84-94,2003$

TORREGROSA, M.L. et al. Cross-comparative report on infrastructure and technology. México: PRINWASS, 2004.
VON SPERLING, M. Constraints to improving water and sanitation services. In: GRABOW, W. (Ed.). Water and Public Health. Encyclopedia of Life Support Systems (EOLSS). Developed under the Auspices of Unesco. Oxford, UK: EOLSS Publishers, 2004. [http://www. eolss.net]

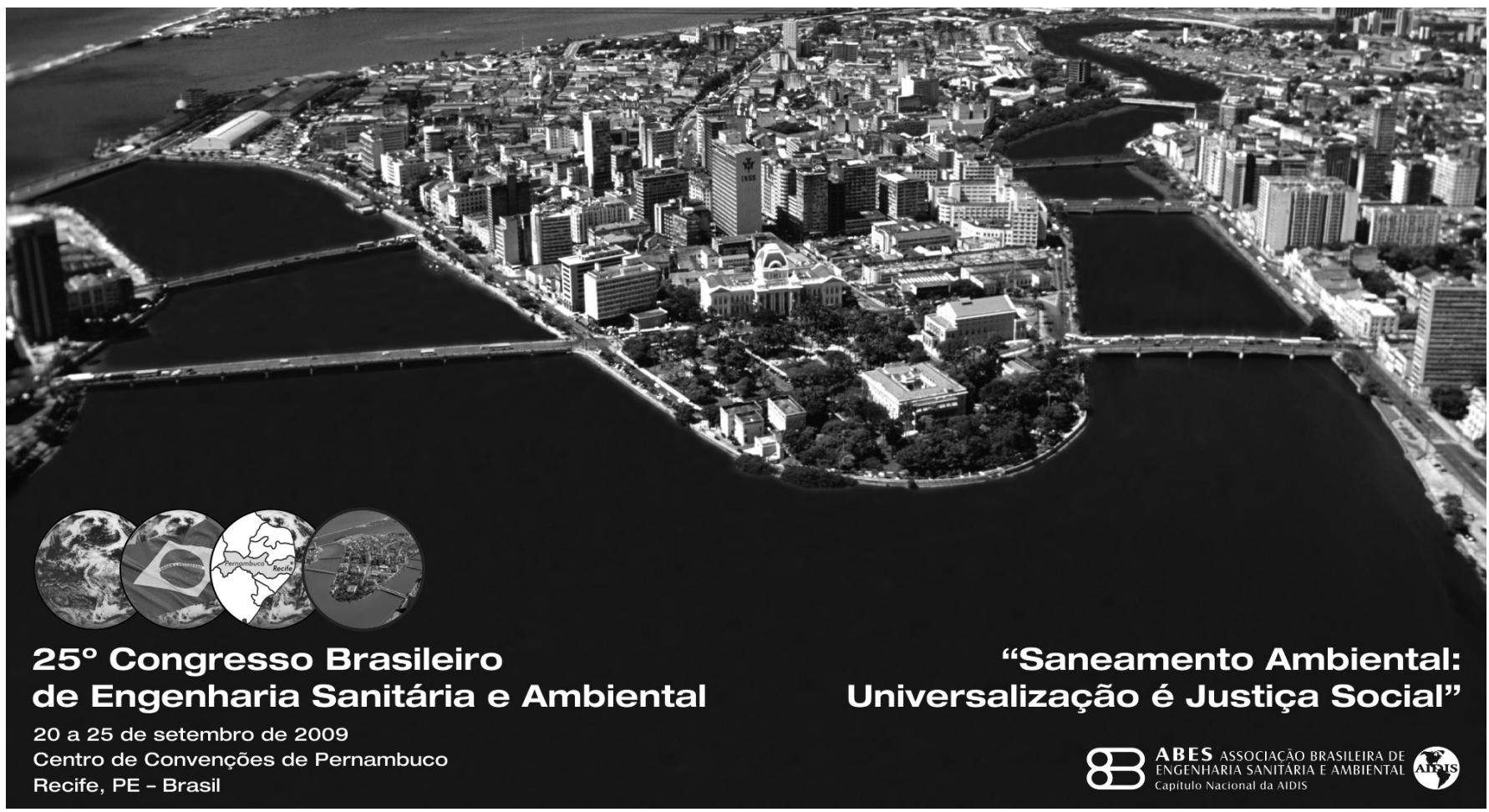

